\title{
Asymmetric Information, Self-selection and Pricing of Insurance Contracts: The Simple No-Claims Case
}

\author{
Catherine Donnelly
}

Martin Englund

Jens Perch Nielsen

Carsten Tanggaard

3 December 2012

\begin{abstract}
This paper presents an optional bonus-malus contract based on a priori risk classification of the underlying insurance contract. By inducing self-selection, the purchase of the bonus-malus contract can be used as a screening device. This gives an even better pricing performance than both an experience rating scheme and a classical no-claims bonus system. An application to the Danish automobile insurance market is considered.
\end{abstract}

Keywords: Adverse selection; Screening device; Insurance pricing; Bonusmalus system.

Catherine Donnelly (corresponding author) is at the Department of Actuarial Mathematics and Statistics, and the Maxwell Institute for Mathematical Sciences, Heriot-Watt University, Edinburgh EH14 4AS, United Kingdom. Donnelly can be contacted via email: C.Donnelly@hw.ac.uk. Martin Englund is at the Department of Economics and Business, Aarhus University, Denmark, and Codan Insurance, part of the RSA Group, Denmark. Englund can be contacted via e-mail: eld@codan.dk. Jens Perch Nielsen is at Cass Business School, City University, 106 Bunhill Row, London EC1Y 8TZ, United Kingdom. Nielsen can be contacted via e-mail: Jens.Nielsen.1@city.ac.uk. Carsten Tanggaard is at CREATES, Aarhus University, Denmark. Tanggaard can be contacted via e-mail: ctanggaard@creates.au.dk.

The authors wish to express their gratitude to an anonymous referee whose comments greatly improved the paper. Carsten Tanggaard acknowledges support from CREATES, funded by the Danish National Research Foundation. 


\title{
INTRODUCTION
}

\author{
If one tells the truth, one is sure, sooner or later, to be found \\ out.
}

Oscar Wilde

In a world with two levels of risk and asymmetric information, where the insurance company cannot distinguish between customers from the two risk groups, there is no pooling equilibrium and there may not be an equilibrium at all (Rothschild and Stiglitz, 1976). In a pooling equilibrium, the lower risk policyholders subsidize the higher risk policyholders. If the policyholders are aware of their risks and the difference is too large between risk and price, the lower risk individuals will not buy insurance. Thus, either the market for insurance breaks down or each type of policyholder buys an insurance contract with a payoff that caters to the specific riskiness of the policyholder. This idea of sufficiently tailor-made (i.e. differentiated) contracts may not fit exactly with what we see in current insurance markets. Insurance contracts offered by insurance companies are only to some extent differentiated, depending on the sophistication of the models, the available data and regulations. However, Allard et al. (1997) show that pooling equilibria may exist if even the slightest distributional cost exists. Differences in risk aversion can also make policyholders with different risks accept pooling (at least to some extent), according to Rothschild and Stiglitz (1976).

Covariate-based regression is generally used to differentiate pricing and the most widely used models for this are generalized linear models (GLM); see Pinquet (2001) for applications in actuarial science and McCullagh and Nelder (1989) for a general discussion of the statistical theory of GLMs. One way to improve the a priori pricing is to make use of a posteriori corrections based on experience rating, such as credibility theory and bonus-malus systems (BMS). Simple time-independent credibility models with extensions to both time-dependence and multivariate experience rating are found in Pinquet et al. (2001) and Englund et al. (2009). Brouhns et al. (2003) provide a quick survey of different types of BMS. Unfortunately, these experience-based methods have a limited impact when individual claim information is rare, as for new policyholders, and it may take several years of observation before the precision is reasonable. However, Donnelly et al. (2013) finds evidence of adverse selection within the Danish automobile insurance market, meaning that the degree of coverage chosen by the policyholder is based on the ex ante assessment that a policyholder makes of his riskiness and wealth. Therefore we seek new ways to differentiate the policyholders by risk at the very outset, i.e. at the time of purchase of the insurance product.

This paper gives examples of an insurance contract which may induce selfselection within the existing risk classes of the rating scheme. The new type of insurance contract has some features that are not found in contracts of standard BMS. Similarly to BMS, the payoff that is offered to policyholders depends on the actual number of experienced claims during each insurance period, but the contract has a more general form of payoff than a standard contract with bonus. The payoff can be tailor-made to individual policyholders' needs or preferences. Implicit in this is the idea that insurance companies should offer a menu of 
contracts in such a way that self-selection is induced among the policyholders. Hence, we allow for an extended individual choice compared to standard BMS.

With such a contract the insurer will be able to differentiate the insurance premium for each period of time to an even greater extent, which makes it more competitive due to the separating effect. This is desirable since adverse selection can cause inefficiency in insurance contracts, reducing the benefit of taking an insurance for the lower classes of risk since the price will be too high in relation to the risk (Akerlof, 1970; Rothschild and Stiglitz, 1976; Stiglitz, 1977). For recent contributions on the subjects of asymmetric information, adverse selection, deductibles and bonus systems, see Snow (2009), Spreeuw and Karlsson (2009) and Kim et al. (2009).

We use policyholder and claims data from a Danish insurance company to investigate the hypothesis that such a contract will in fact induce self-selecting behavior, in addition to the decision of buying the insurance, at the differentiated prices of the rating scheme. Other recent approaches to assessing individual customer risk and relating it to pricing are Guillén et al. (2012) and Thuring et al. (2012).

The paper is arranged as follows. In the section titled "The New Insurance Contract", a heterogeneity model for the data and the new insurance contract are defined. "Comparison of the Add-On to Other Pricing Methods" gives the first numerical study, as well as describing the data set and the pricing methods used to measure the pricing precision of the new insurance contract. In the section titled "Individual Choice and Self-Selection", we investigate the effects of individual choice on the pricing precision, based on an expected utility representation and private information. We finish with "Conclusion."

\section{THE NEW INSURANCE CONTRACT}

First, a model for insurance claims when policyholders are heterogeneous is presented. Second, the insurance contract is introduced to exhibit features useful for inducing self-selection among insurance customers. Finally, we illustrate the efficiency of the proposed insurance contact using Danish automobile insurance data.

The usual assumptions used in models on adverse selection are maintained in this paper: individual information is costly to observe by the insurer, neither the frequency nor the claim size are functions of the actions of the policyholders, the provision of the insurance is costless and the insurer is risk-neutral while the policyholders are risk-averse, having the same twice-differentiable, increasing and strictly-concave utility function $U$.

\section{A Model for Heterogeneous Policyholders}

Let us consider the number of claims, $N_{i j}$, for individual $i \in\{1, \ldots, I\}$ in insurance period $j \in\left\{1, \ldots, J_{i}\right\}$ on one particular coverage (i.e. a product). We consider one coverage at a time and assume that the events in different coverages are independent. We assume that every policyholder has a latent individual risk profile $\theta_{i}$, which summarizes the informational asymmetry and is a realization of a positive random variable $\Theta_{i}$. The latent variable $\Theta_{i}$ is considered to be a random effect for the insurer but known by the policyholder. 
Conditional on $\Theta_{i}=\theta_{i}$, the number of claims $N_{i j}$ is assumed to be Poisson distributed with expectation $\nu_{i j} \theta_{i}$, in which $\nu_{i j}>0$ allows for the insurer's prior knowledge about the individual $i$ in time period $j$. Specifically, denoting by $\mathbf{x}_{i j} \in \mathbb{R}^{k}$ a column vector of covariates, such as age, sex, geographical area, or other relevant variables, and by $\omega_{i j}$ the duration of period $j$ covered for policyholder $i$, then

$$
\nu_{i j}=\omega_{i j} \exp \left(\mathbf{a}^{\top} \mathbf{x}_{i j}\right)
$$

in which the constant $\mathbf{a} \in \mathbb{R}^{k}$ is a column vector of parameters and $\mathbf{a}^{\top}$ denotes the transpose of $\mathbf{a}$. When covariates are used to price insurance, it is assumed that individuals with the same characteristics have the same risk. However, the introduction of an individual risk profile into the model means that policyholders with the exact same set of covariates may differ in risk due to unobservable characteristics. Examples of these unobservable characteristics for automobile insurance may be aggressiveness while driving and the temperament of the driver.

The pairs $\left(\Theta_{1}, N_{1 j}\right),\left(\Theta_{2}, N_{2 j}\right), \ldots,\left(\Theta_{I}, N_{I j}\right)$ are independent random vectors, where $\Theta_{1}, \Theta_{2}, \ldots$ are independent and identically distributed (iid) random variables with $\mathbb{E}\left(\Theta_{i}\right)=1$ and $\operatorname{Var}\left(\Theta_{i}\right)=\tau^{2}$.

Since we will only consider full coverage insurances in what comes next, the cost of claims will not affect the individual decision rules or choices. Hence, we consider only the number of claims $N_{i j}$ rather than the aggregate cost of the claims made by individual $i$ in insurance period $j$.

Suppose that the insurer wishes to price the contract at the actuarially fair value. If the latent individual risk profile $\theta_{i}$ is observable by each policyholder and insurer, then we have symmetric information. In that case, the insurance contract is simple: in each period the insurer offers to cover all losses for each individual against an insurance premium

$$
\mu_{i j}\left(\theta_{i}\right):=\mathbb{E}\left(N_{i j} \mid \Theta_{i}=\theta_{i}\right)=\nu_{i j} \theta_{i} .
$$

However, when the insurer cannot observe the latent individual risk profile $\theta_{i}$, the actuarially fair value of the insurance premium is

$$
\mu_{i j}:=\mathbb{E}\left(\mu_{i j}\left(\Theta_{i}\right)\right)=\nu_{i j} \mathbb{E}\left(\Theta_{i}\right)=\nu_{i j} .
$$

In the latter case of asymmetric information, there is no adjustment to the insurance premium for the individual's risk profile. In the following section we propose a way to enable the insurer to gain information about the individual's risk profile $\theta_{i}$.

\section{The Add-On to the Standard Insurance Contract}

Now we consider an add-on to the standard insurance contract, which allows for the policyholder's individual risk profile $\theta_{i}$. To keep the discussion simple, we assume that the discount rate is zero ${ }^{1}$.

In addition to the premium $\mu_{i j}$, policyholder $i$ who accepts the add-on will pay an entrance fee $\pi_{i j}>0$. If the policyholder makes no claims during the insurance period $j$, the insurer will pay an amount $\pi_{i j}+d_{i j}$ to the policyholder, in

\footnotetext{
${ }^{1}$ Lazar and Denuit (2012) is a recent analysis of the relationship of premiums with interest rates, among other variables.
} 
which the constant $d_{i j}>0$ is called the dividend. In other words, a policyholder who makes no claims during the insurance period $j$ gets back their entrance fee plus a dividend at the end of the insurance period $j$. If the policyholder makes one claim or more, then the insurer pays nothing to the policyholder in respect of the add-on (although the cost of the claims made under the standard insurance contract are covered as usual). The add-on to the standard insurance contract has a binary nature: either policyholder $i$ gets the payment $\pi_{i j}+d_{i j}$ at the end of insurance period $j$, or they do not.

We focus our analysis on the simplest (one-period) setting in which the addon is a one-period contract. Policyholders decide at the start of the insurance period whether or not to accept the add-on, and the contingent payment made at the end of the insurance period is distinct from the premium that would be paid in the next insurance period. Extensions of this simple setting are discussed in the following subsection, "Discussion of the Add-On."

We assume that the contingent payment $\pi_{i j}+d_{i j}$ is made directly to policyholder $i$ at the end of the insurance period $j$. In a more realistic setting, it may be tax-efficient to reduce instead the insurance premium in the subsequent insurance period by the amount of the contingent payment. ${ }^{2}$

The payments in the add-on could be re-structured so that the policyholder pays nothing at the start of the insurance period. Then if policyholder $i$ makes no claims, they would receive a payment of $d_{i j}$ from the insurer at the end of the insurance period $j$. Otherwise, policyholder $i$ pays $\pi_{i j}$ to the insurer at the end of the insurance period $j$. All of the results in our simple setting are identical with this alternative payment structure. It also allows the identification of the payment $d_{i j}$ as a bonus and the payment $\pi_{i j}$ as a malus.

However paying the entrance fee $\pi_{i j}$ up-front has the advantage of allowing us to bypass punishment rules in environments where they are forbidden, such as in some health insurance systems; for example, see Riedel (2006). The absence of a reward at the end of the insurance period in the case where no-claims occur (i.e. receiving nothing) replaces the punishment decision of the alternative payment structure (i.e. having to pay a malus $\pi_{i j}$ to the insurer). It may also be more attractive way of framing the add-on to the policyholder (see Johnson et al. (1993)). Note that BMSs come in many variants in real life, as well as in the literature; for the latter, examples are Baione et al. (2002); Denuit et al. (2007); Lemaire and Zi (1994); Lemaire (2006); Moreno et al. (2006); Pinquet (1997).

Mathematically, the payment from the add-on to policyholder $i$ at the end of insurance period $j$ is represented by the random variable

$$
D_{i j}:= \begin{cases}\pi_{i j}+d_{i j} & \text { if } N_{i j}=0 \\ 0 & \text { if } N_{i j}>0\end{cases}
$$

When making decisions regarding the add-on, the policyholder will take into account their conditional probability of claims

$$
p_{i j}\left(\theta_{i}\right):=\mathbb{P}\left(N_{i j}>0 \mid \Theta_{i}=\theta_{i}\right) .
$$

Thus the conditional distribution of $D_{i j}$ is

$$
\left(D_{i j} \mid \Theta_{i}=\theta_{i}\right)= \begin{cases}\pi_{i j}+d_{i j} & \text { with probability } 1-p_{i j}\left(\theta_{i}\right) \\ 0 & \text { with probability } p_{i j}\left(\theta_{i}\right) .\end{cases}
$$

\footnotetext{
tax.

${ }^{2}$ Ulm (2012) considers the pricing of insurance contracts in a broader framework involving
} 
Having described the structure of the add-on, it remains to fix the values of the entrance fee $\pi_{i j}$ and the dividend $d_{i j}$. The entrance fee, $\pi_{i j}$, can be set either individually or collectively. This will be a strategic decision of the insurer and something we discuss in the sequel.

The dividend $d_{i j}$ is calculated in this paper via the actuarial net premium principle; see Young (2006). The net premium principle is justifiable if we can assume that volatility is essentially nonexistent, that is if the insurer sells enough iid policies so that the Law of Large Numbers applies. However, the dividend can be calculated via any other suitable principle, e.g. the expected value premium principle: $\pi_{i j}=(1+\xi) \mathbb{E}\left[D_{i j}\right]$, for some $\xi>0$.

Under the actuarial net premium principle, we set the entrance fee equal to the expected payment from the add-on, i.e.

$$
\pi_{i j}=\mathbb{E}\left[D_{i j}\right] .
$$

We assume that the insurer must offer the add-on contract ex ante to the policyholder, with the amounts $\pi_{i j}$ and $d_{i j}$ fixed at the start of insurance period $j$. The insurer cannot change $\left(\pi_{i j}, d_{i j}\right)$ during insurance period $j$ in light of the decision of policyholder $i$ to accept the add-on or not. This does not preclude the insurer from changing the risk classification of policyholder $i$ in subsequent insurance periods, based on their decision to accept the add-on in the current insurance period. We do not explore this interesting avenue of research in the current paper. Instead our focus is on the pricing precision of the add-on within the current insurance period. This is important to know, to see if there is a cost to the insurer in offering the add-on. In fact, our results show that the insurer's pricing precision may be increased significantly by offering the add-on.

Defining the unconditional probability of claims of policyholder $i$ in insurance period $j$

$$
p_{i j}:=\mathbb{E}\left[p_{i j}\left(\Theta_{i}\right)\right],
$$

the (unconditional) distribution of $D_{i j}$ is

$$
D_{i j}= \begin{cases}\pi_{i j}+d_{i j} & \text { with probability } 1-p_{i j} \\ 0 & \text { with probability } p_{i j} .\end{cases}
$$

Substituting $\mathbb{E}\left[D_{i j}\right]=\left(1-p_{i j}\right)\left(\pi_{i j}+d_{i j}\right)$ into equation (1), we get

$$
\frac{d_{i j}}{\pi_{i j}}=\frac{p_{i j}}{\left(1-p_{i j}\right)} .
$$

Once the insurer has chosen $\pi_{i j}$, the value of the dividend $d_{i j}$ is fixed by the above equation. Note that the insurer sets the dividend based on $p_{i j}$, the average probability of making a claim. In comparison, the policyholder evaluates the offered contract based on their individual probability of making a claim, $p_{i j}\left(\theta_{i}\right)$.

\section{Discussion of the Add-On}

The add-on is a voluntary investment in addition to the original insurance contract. The add-on should be appealing to the customer who is a better-thanexpected risk. Assuming this attractiveness is communicated to the customer, it is then for the customer to judge if he is a better-than-expected type. In this sense, there is a clear incentive from the customer's perspective to reveal 
his private knowledge. Consequently, the add-on is linked more directly to the economic discussion of asymmetric information than are classical BMSs.

Superficially, it seems that our simple no-claims example is similar to a "money-back" structure because money is paid out at the end of a claim-free year. Indeed, in the one-period case, the add-on clause has many similarities to a BMS. This can be seen by assuming a multi-period setting in which the payments from the one-period add-on are paid only upon renewal of the insurance contract in the subsequent insurance period. In that case, the add-on is not very different from a BMS in the long run.

However, when generalizing the basic idea of paying money upfront, i.e. the entrance fee, to more complex pricing structures, such generalizations would differ fundamentally from other natural developments of a BMS. We could construct an add-on that is a five-year or ten-year contract rather than a one-year contract. A long-term contract gives the customer the full advantage of being a better-than-expected risk at the same time as providing a clear customer loyalty situation for the company. Furthermore, the add-on does not have to be restricted to the simple no-claims case. For example, one could introduce a threshold such the customers can have claims paid out up to some amount while still being in the class of customers getting a payout. Or one could simply say that the customer pays his own claims with the revenue from the add-on contract, as long as the revenue is large enough to pay the claims.

For example, suppose that the add-on is a five-year contract. At the start of the five-year period, the customer pays the standard insurance premium and the entrance fee. The entrance fee is calculated using the customer's expected experience over the five-year period, rather than on observed experience data. During the five years, the standard insurance premium is adjusted using the emerging experience. The new idea is that we adjust also a historically alreadypaid premium. Aside from the initial entrance fee, the contract is structured so that the customer does not pay any more in premiums than if he had not bought the add-on. In other words, the buyer of the add-on cannot lose more than the entrance fee. That leaves the insurance company with a risk for which they charge an insurance premium in a similar way to the one-period case considered in this paper. The distinction of moral hazard and dynamic selection on unobservables as analysed in Abbring et al. (2003b,a) based on observed data might be further developed and improved while incorporating future data in the consideration.

\section{COMPARISON OF THE ADD-ON TO OTHER PRICING METHODS}

We want to compare the insurance contract with a one-year add-on against different pricing methods, using Danish automobile insurance data from 2001 to 2004. The accuracy of each pricing method is assessed by estimating the sum of squared errors (SSE), across all individual policyholders. Here, the error is defined as the net payment made by the insurer to the policyholder during an insurance period. The most efficient pricing method is the one which has the lowest SSE.

The idea behind using the SSE is that the insurer wants to break-even on 
each contract. A premium which is too low will result in an economic loss. A premium which is too high will result in a loss of policyholders to another insurer who is offering a lower premium. More precisely, and since we only will investigate the product portfolio of one insurer, we assume that the insurer is a risk-neutral competitive specialist, whose expected profit for each policy is zero, as in Glosten and Milgrom (1985). The minimum SSE is expected in the theoretical situation where each customer pays exactly his own claim costs to the insurance company. Although the results below should clearly be interpreted in light of this, a low SSE seems to be a reasonable description of the insurance company's optimization problem (Bühlmann and Gisler, 2005).

\section{Data Preparation and Model Validity}

The data set that we analyze consists of $I=8337$ policyholders in the personal lines portfolio of a Danish insurance company. The data set contains the variables used by the pricing department at the insurance company for each of the years during the period. For example, the covariates are: policyholder's demographic characteristics such as age, gender, geography; policyholder's car characteristics: brand, size of engine, model year, initial value of the car, commercial vehicle or not, main vehicle or not.

The data set was selected from more than 375000 policyholders in the same portfolio. Policyholders with missing values and obvious outliers were removed. We chose the policyholders with exactly one automobile insurance policy, which has full coverage, full duration for each year of the period $2001-2004$ and with no experience rating. In order to compare the classical no-claims bonus with the add-on as far as possible, each policyholder has to fulfill the criteria of the classical bonus, to the extent that the bonus is only dependent on the claim experience. Therefore we further restricted our selection to policyholders who, in addition to the automobile insurance, have purchased a building and personal property insurance policy with full duration in the period $2001-2004$.

The actual number of claims experienced for policyholder $i$ in year $j$ is denoted $n_{i j}$ and, as all policies have full annual duration, $\omega_{i j}=1$. By a covariatebased regression method (using GLM and maximum likelihood), we obtained the estimated expected number of claims $\tilde{\nu}_{i j}$. However, in our data set there is a difference between the total expected and total experienced number of claims due to the pricing procedure, namely the rating scheme is estimated on all policyholders of the automobile portfolio, while we use only a subset of these. One might suspect that policyholders with full duration in four consecutive years, and who have purchased at least three insurance products, have a better claim history than we expected, even though total duration (seniority) is not a significant variable in the rating scheme. Due to this difference and our interest to investigate the performance of various pricing methods, we scaled the original claim frequency estimates $\tilde{\nu}_{i j}$ of the regression by multiplying each of them by a factor $\sum_{i=1}^{I} \sum_{j=2001}^{2003} n_{i j} / \sum_{i=1}^{I} \sum_{j=2001}^{2003} \tilde{\nu}_{i j}=0.9164$. These new claim frequency estimates $\hat{\nu}_{i j}$ were then used to perform the analyses of this paper.

Table 1 summarizes the claim information for each year in the period $2001-$ 2004 for the data set of $I=8337$ policyholders.

\section{*** Insert Table 1 about here ***}


Empirically, we get a dispersion index of 1.33 for the data set which supports the correctness in assuming a conditional Poisson distribution, i.e. assuming the existence of an individual latent risk profile.

\section{Pricing Methods}

We investigated five pricing methods for the insurance contract. The premiums for the year 2004 were calculated based on the data in in years $2001-2003$. The premiums and the actual claims experience in 2004 were then used to calculate the SSE for each method.

The five pricing methods, with their numerical index, are the following:

1. Flat rate. The mean value estimator, or the flat rate, method with insurance premium $\hat{\mu}_{i j}^{(1)}$. For this pricing method, the premium charged is identical for all policyholders:

$$
\hat{\mu}_{i j}^{(1)}:=\hat{\mu}^{(1)}:=\frac{\sum_{i=1}^{I} \sum_{j=2001}^{2003} n_{i j}}{\sum_{i=1}^{I} \sum_{j=2001}^{2003} \omega_{i j}} .
$$

The flat rate method is the simplest possible estimator with an expected non-negative profit. Based on the data in years $2001-2003$, we find $\hat{\mu}^{(1)}=0.2091$, meaning that, on average, there is approximately one claim every fifth year.

2. Regression. The covariate-based regression method with insurance premium $\hat{\mu}_{i j}^{(2)}=\hat{\nu}_{i j}$. It is the pricing method used by the Danish insurance company from whom we obtained the data and we use it as the baseline pricing method.

3. Credibility. The experience rating method based on the one-dimensional homogeneous credibility estimator, with insurance premium $\hat{\mu}_{i j}^{(3)}=\hat{\mu}_{i j}^{(2)} \widehat{\theta_{i j}}$. Bühlmann and Gisler (2005) provide an excellent survey on credibility theory.

4. No-claims BMS. The classical, market-based, no-claims BMS with premium $\hat{\mu}_{i j}^{(4)}$. In this case, if certain critera are satisfied, the policyholder is granted a bonus expressed as a percentage of the premium. The bonus is given if the following criteria are fulfilled: the policy has a duration of at least three years, no claims are reported during both the last three years and the current insurance period. For the given data set, the bonus is $10 \%$. Normally, this requires that all policyholders pay $3-4 \%$ more of the original actuarial premium up-front, in order that the portfolio is financially balanced. However, for the data subset of $I=8337$ policyholders, the additional payment is $9.533 \%$. The reason is due to the data selection: every policyholder in the data subset is in the bonus system and has the opportunity of getting a bonus. We lack the policyholders who subsidize the bonus system by not having the opportunity of getting one. Consequently the additional payment is higher.

5. Add-on. The standard insurance contract with an add-on. The premium charged for the standard insurance contract is $\hat{\mu}_{i j}^{(2)}$ and the entrance fee 
for the add-on is $\pi_{i j}$. In this section of the paper, we assume that all policyholders buy the add-on, so that the total amount charged to policyholder $i$ is $\hat{\mu}_{i j}^{(5)}=\hat{\mu}_{i j}^{(2)}+\pi_{i j}$. This assumption will be removed in the section "Individual choice and self-selection".

The dividend of the add-on is calculated for each policyholder $i$ through equation (2). This requires an estimator of $p_{i j}=\mathrm{E}\left[p_{i j}\left(\Theta_{i}\right)\right]$. First we expanded $p_{i j}\left(\Theta_{i}\right)=1-e^{-\nu_{i j} \Theta_{i}}$ as a second-order Taylor series around $\mathbb{E}\left(\Theta_{i}\right)=1$, with a remainder term. Based on the data set, the empirical mean value of the remainder term is negligible (it is less than 0.00175). Hence, taking the expectation of the Taylor expansion, we assumed the expected value of the remainder term was zero. The resulting estimator is $\hat{p}_{i j}=1-e^{-\nu_{i j}}-\frac{1}{2} \nu_{i j}^{2} e^{-\nu_{i j}} \tau^{2}$, in which $\tau^{2}:=\operatorname{Var}\left(\Theta_{i}\right)$.

Figure 1 shows the distribution of $\hat{r}_{i, 2004}:=\hat{p}_{i, 2004} /\left(1-\hat{p}_{i, 2004}\right)$ in the data set. The dividend is calculated as $d_{i, 2004}=\hat{r}_{i, 2004} \pi_{i, 2004}$ for each policyholder $i$. Thus each policyholder $i$ is offered an individually-determined add-on, with entrance fee $\pi_{i, 2004}$ and dividend $d_{i, 2004}$. We discuss below the choice of the entrance fee.

\section{A First Numerical Study}

As we assume that the cost of claims $S_{i j}=1$, the SSE for pricing methods $l=1,2,3,4$ is defined as

$$
\operatorname{SSE}(l, j)=\sum_{i=1}^{I}\left(\hat{\mu}_{i j}^{(l)}-n_{i j}\right)^{2} .
$$

Due to the structure of the add-on, we calculate the SSE for $l=5$ as

$$
S S E(l=5, j)=\sum_{i=1}^{I}\left(\hat{\mu}_{i j}^{(5)}-n_{i j}-\left(d_{i j}+\pi_{i j}\right) \mathbb{1}\left[n_{i j}=0\right]\right)^{2},
$$

in which $\mathbb{1}\left[n_{i j}=0\right]$ equals one if $n_{i j}=0$, and zero otherwise.

Instead of reporting the absolute values of the SSE, we use the scaled SSE for each pricing method. It is calculated by dividing $S S E(l, 2004)$ by $S S E(2,2004)$, i.e. the SSE of the regression method, for each $l=1, \ldots, 5$.

To fix the entrance fee $\pi_{i, 2004}$ for the add-on, in this section we assume it is a constant multiple of the premium $\hat{\mu}_{i, 2004}^{(2)}$ charged for the standard insurance contract to policyholder $i$. Investigating the scaled SSE for the interval $\hat{\pi}_{i, 2004} / \hat{\mu}_{i, 2004}^{(2)} \in[0,5]$, we obtained Figure 2 .

\section{*** Insert Figure 2 about here $* * *$}

The minimum SSE for the add-on contract occurs at $\tilde{\pi}_{i, 2004}=3.357 \hat{\mu}_{i, 2004}^{(2)}$ across the data set. We used this choice of the entrance fee to compare the pricing precision of the add-on contract with the other pricing methods. The results are shown in Table 2.

*** Insert Table 2 about here 
The difference in performance of the flat rate and the regression estimator is quite important since it illustrates why insurance companies have pricing departments. The credibility method, no-claims BMS method and add-on method all use individual claim information. Therefore, they are expected to perform better than the other two ones, as is borne out by the numerical results.

Table 2 shows that the credibility method gives an additional improvement of $25 \%$ over the regression method relative to the improvement due to moving from the flat rate method to the regression method. Even so, it is not as good as we anticipated based on earlier studies, such as Englund et al. (2008) and Englund et al. (2009). However, the performance of a pricing method also depends on the type of coverage and data set. It may be that our data set is too limited; four years may be too few to fully benefit from the credibility approach.

In comparison, the performance of the no-claims BMS method is surprisingly good. It gives an additional improvement of $54 \%$ over the regression method compared with moving from the flat rate method to the regression method. It is also a rather simple method. These type of classical bonus systems are however afflicted with some drawbacks regarding fairness and stability aspects. Fairness: giving a fixed percentage in bonus is advantageous for the expected low-risk policyholders and disadvantageous for the expected high-risks compared to their probability of reporting claims. However, if the insurer has a strategy towards expected low-risks then it can be justified, or at least explained by, the insurer. Stability: if all customers qualify for the bonus system (for example, they purchase the required number of products), then the system would not be stable, in the sense that the insurer will lose money if the initial extra payment is not re-estimated. Remember that one of the fundamental principles of insurance is that the policyholder should pay for the expected transferred risk, not the outcome.

The add-on deals with these fairness and stability aspects while retaining the advantages of simplicity and low requirements on information. It can perform even better than both the credibility method and the $10 \%$ no-claims BMS, depending on the choice of the entrance fee $\hat{\pi}_{i j}$. The scaled SSE of the add-on with the optimal entrance fee $\tilde{\pi}_{i, 2004}=3.357 \hat{\mu}_{i, 2004}^{(2)}$ is exceptionally low, and it is almost 20 times the improvement of implementing the regression method over the flat rate method.

The drawback is that the optimal entrance fee is over three times the premium. It is doubtful that an average policyholder would pay the optimal entrance fee of more than three times their annual insurance premium up-front and risk losing it all. For these reasons, and encouraged by the promising results in Table 2, we extend our study to allow for the policyholders to choose whether or not to buy the add-on.

\section{INDIVIDUAL CHOICE AND SELF-SELECTION}

In the previous section we saw that the pricing precision could be increased by setting individual risk-based bonuses. However, the analysis was under the assumption that all the policyholders bought the add-on, no matter how high the entrance fee. Here we relax the assumption.

Each policyholder buys the standard insurance contract, and then decides whether or not to buy the add-on. We expect that this will induce self-selection 
among policyholders within the same risk class of the rating scheme. The policyholders make their choice based on an expected utility decision rule, namely they buy the add-on if it gives them a higher expected utility of wealth compared to not buying the add-on. Thus we are introducing the individual risk preferences of the policyholders.

As we are interested in the performance of the add-on both as a pricing method and as a separating (self-selection) mechanism, we focus only on the decision to buy the add-on or not, and ignore the decision on whether to buy insurance or not. Moreover, for the numerical study below, the individuals in the data set have already decided to buy insurance. As before, we assume a null discount rate.

\section{The Individual Decision Rule}

Denote by $w_{i j}$ the wealth of individual $i$ at the start of insurance period $j$, i.e. the initial wealth prior to the decision about insurance coverage. The initial wealth consists of all the policyholder's possessions including cash, financial assets, and the object that is insured. The policyholder is assumed to have more wealth than the insured object and enough cash to pay the premium $\mu_{i j}$ of the standard insurance contract and the entrance fee $\pi_{i j}$, i.e. $w_{i j}>\pi_{i j}+\mu_{i j}$. Although there is no need to have the " $j "$ subscript in this section, we maintain it here for consistency with the notation in the rest of the paper.

There are only two different outcomes for the terminal wealth depending on the binary decision on whether to buy insurance with or without an add-on. The outcomes are summarized in Table 3 .

\section{*** Insert Table 3 about here $* * *$}

It follows that the policyholder will decide to buy the add-on if

$$
\mathbb{E} U\left(w_{i j}-\mu_{i j}-\pi_{i j}+D_{i j} \mid \Theta_{i}=\theta_{i}\right)>U\left(w_{i j}-\mu_{i j}\right),
$$

that is

$$
p_{i j}\left(\theta_{i}\right) U\left(w_{i j}-\mu_{i j}-\pi_{i j}\right)+\left(1-p_{i j}\left(\theta_{i}\right)\right) U\left(w_{i j}-\mu_{i j}+d_{i j}\right)>U\left(w_{i j}-\mu_{i j}\right) .
$$

We assume the policyholder to have a Constant Relative Risk Aversion (CRRA) utility function. For $w>0$, the CRRA utility function is defined as

$$
U(w)= \begin{cases}\frac{w^{1-\gamma}}{1-\gamma}, & \gamma \neq 1 \\ \ln (w), & \gamma=1 .\end{cases}
$$

The choice of CRRA finds support in Friend and Blume (1975), Pindyck (1988) and Szpiro (1986). Friend and Blume conclude that an individual's coefficient of relative risk aversion is "on average well in excess of one and probably in excess of two", based on data on household asset holdings. Pindyck finds support for a relative risk aversion coefficient between 3 and 4 whereas Szpiro finds support for a relative risk aversion coefficient between 1.2 and 1.8, based on data on property/liability insurance. In our simple scenario, we assume a relative risk aversion coefficient $\gamma=2$, and investigate a number of alternative scenarios in which we alter the initial wealth and other parameters. 
Define

$$
\beta_{i j}:=\frac{\pi_{i j}}{w_{i j}-\mu_{i j}} \quad \text { and } \quad r_{i j}:=\frac{d_{i j}}{\pi_{i j}} .
$$

We call $\beta_{i j}$ the investment ratio for policyholder $i$ in insurance period $j$. Under the CRRA assumption, we can rewrite the decision rule (3) as ${ }^{3}$

$$
p_{i j}\left(\theta_{i}\right)<\frac{U\left(1+r_{i j} \beta_{i j}\right)-U(1)}{U\left(1+r_{i j} \beta_{i j}\right)-U\left(1-\beta_{i j}\right)} .
$$

In other words, for an arbitrary policyholder with a fixed risk aversion coefficient $\gamma$, their decision to buy the add-on depends on three things: their individual conditional probability of claim $p_{i j}\left(\theta_{i}\right)$, the ratio $r_{i j}$, and the investment ratio $\beta_{i j}$.

If we further specialize to the case where the ratio $r_{i j}$ is determined by the insurer through equation (2) and the relative risk aversion coefficient $\gamma=2$, the decision rule reduces to

$$
p_{i j}\left(\theta_{i}\right)<\left(1-\beta_{i j}\right) p_{i j} .
$$

Thus in this simple scenario, as the entrance fee decreases and hence $\beta_{i j}$ decreases, more policyholders will accept the add-on. Additionally, we see that as long as a policyholder's conditional probability of claim $p_{i j}\left(\theta_{i}\right)$ is less than the average probability of claim $p_{i j}$, it is possible to find an investment ratio at which the policyholder will buy the add-on. However, we do not explore further in this paper precisely how the add-on can act as a screening device. Instead, we analyze the impact on the SSE of allowing the policyholders the choice to buy the add-on, and how the SSE varies with different investment ratios offered to the policyholders.

\section{A Second Numerical Study}

On the Danish data set of $I=8337$ policyholders, we investigate three scenarios for the selection of the investment ratio using the decision rule (5). First, all policyholders are offered the same investment ratio $\beta$. Next, each policyholder is offered the investment ratio which maximizes their individual expected utility from the purchase of the add-on. Lastly, the policyholders are offered an entrance fee that is the same constant multiple of their standard insurance premium across all policyholders.

We use the regression method to calculate the premium for the standard insurance contract. As before, the parameters are estimated from the data in years 2001-2003. In particular, the (private) risk profile $\theta_{i}$ of each policyholder is taken to be their second last credibility estimate, based on the information in years 2001-2003.

In the first scenario, all policyholders are offered the same investment ratio, i.e. $\beta_{i, 2004}=\beta$ for all $i$. Thus policyholder $i$ is offered an add-on with entrance fee $\pi_{i, 2004}=\beta\left(w_{i, 2004}-\mu_{i, 2004}\right)$ and dividend $d_{i, 2004}=r_{i, 2004} \pi_{i, 2004}$. Note that, under the decision rule (5), each policyholder evaluates the add-on based on $\beta$, and not directly on the entrance fee $\pi_{i, 2004}$ or their initial wealth $w_{i, 2004}$. Figure 3 shows how many policyholders would choose to buy the add-on at different levels of $\beta$.

\footnotetext{
${ }^{3}$ We thank the referee for pointing out this approach.
} 


\section{$* * *$ Figure 3 about here***}

Under the first scenario, we find which investment ratio $\beta$, offered to all the policyholders at the start of 2004 , would have minimized the SSE at the end of 2004. Of course, this is not a method that an insurer could use a priori to select the investment ratio. However, it does give us some insight into the potential offered by add-on. Since we do not know the wealth of each policyholder, the analysis is done assuming that all policyholders start the year 2004 with the same amount of wealth. The results are summarized in Table 4.

\section{$* * *$ Table 4 about here ${ }^{* * *}$}

In Table 4, we see that the optimal constant investment ratio offered to the entire portfolio is decreasing as the initial wealth increases. The consequence is that the SSE decreases as wealth increases, since each policyholder is bearing more of their own risk. The increasing number of policyholders buying the add-on is due to the decreasing $\beta$, under the assumption that the risk aversion coefficient remains constant. Notable is that, for $\beta=0.06203$, the entrance fee is around DKK 620 (ignoring the premium for the standard insurance contract, as it varies between policyholders) and already we get an additional improvement in the SSE of $81.79 \%$ compared going from the flat rate to the regression estimator. Just by adding individual choice!

The average experienced claim frequency in year 2004 for the policyholders who buy an add-on at these portfolio optimal investment ratios is $18.84 \%$, while it is $22.65 \%$ for those who do not buy the add-on. As $p_{i j}$ and $p_{i j}\left(\theta_{i}\right)$ are estimated from the data in years 2001-2003, this means that the policyholders who decide to buy the add-on continue to show lower risk in the year 2004.

In the next scenario, we suppose that the insurer offers to each policyholder $i$ the investment ratio $\tilde{\beta}_{i, 2004}$ that maximizes their expected utility from the add-on (i.e. the $\tilde{\beta}_{i, 2004}$ that maximizes the left-hand side of equation (3)). This means that policyholder $i$ is offered an add-on with entrance fee $\pi_{i, 2004}=$ $\tilde{\beta}_{i, 2004}\left(w_{i, 2004}-\mu_{i, 2004}\right)$ and dividend $d_{i, 2004}=r_{i, 2004} \pi_{i, 2004}$. If the decision rule (5) is satisfied for this choice of the investment ratio $\tilde{\beta}_{i, 2004}$, then policyholder $i$ will buy the add-on. Figure 4 shows the distribution of the estimated values of the optimal individual investment ratios $\tilde{\beta}_{i, 2004}$ across the data set.

\section{$* * *$ Figure 4 about here ${ }^{* * *}$}

In total, 5246 policyholders will choose to buy the add-on at their individually optimal $\tilde{\beta}_{i, 2004}$. Table 5 shows the scaled SSE under different assumptions on the initial wealth, under this scenario.

\section{$* * *$ Table 5 about here ${ }^{* * *}$}

We get an even better pricing method than in the first scenario for all assumptions on initial wealth. However, in practice, for policyholders with large initial wealths, such as DKK 1000 000, there should be some restrictions for the entrance fee to be a good pricing method. For instance, a restriction could be that the net dividend $d_{i j}$ may not exceed the actuarial premium, or else the SSE will increase as the dividend increases. For implementational reasons, the insurer might offer the policyholder with a stepwise function, instead of 
a continuum of eligible entrance fees. The precision of the function may depend on the precision of risk perception of the policyholders and the costs of implementation, systems maintenance and so on.

We find that the average experienced claim frequency in year 2004 for those policyholders who buy an add-on at their individually optimal investment ratio $\tilde{\beta}_{i, 2004}$ is $20.85 \%$, while it is $21.00 \%$ for those who do not buy the add-on. Thus, while policyholders who decide to buy the add-on continue to show lower risk in the year 2004, the difference in risk is not as large as in the first scenario, in which all policyholders were offered the same constant investment ratio.

In the last scenario, each policyholder is offered an entrance fee which is a proportion of their individual standard insurance premium. It is the same scenario as in the subsection "A First Numerical Study", except that now the policyholders make a decision to accept the add-on or not. For some constant $k>0$, policyholder $i$ is offered an add-on with entrance fee $\pi_{i, 2004}=k \mu_{i, 2004}$ and dividend $d_{i, 2004}=r_{i, 2004} \pi_{i, 2004}$. The motivation is that it might be easier to relate to the insurance premium than the initial wealth, for both the policyholder and the insurer. The proportion $k$ is chosen as the one which would have minimized the SSE at the end of year 2004. Table 6 shows the results, assuming all policyholders have the same initial wealth.

\section{$* * *$ Table 6 about here ${ }^{* * *}$}

The scaled SSEs in Table 6 are less than under the no-claims BMS method (whose scaled SSE is 0.9828; see Table 2), except at an initial wealth $w_{i, 2004}=$ 10000 . The performance is improving as the initial wealth increases, but so is the entrance fee.

Generally the SSE is somewhat higher than in the other two scenarios, for the same initial wealth (compare Table 6 with Table 4 and Table 5). In spite of this, the number of policyholders buying the add-on is larger than in the scenario in which all policyholders were offered the same investment ratio (compare Table 6 with Table 4).

The average experienced claim frequency in year 2004 for those policyholders who buy an add-on when the proportion $k$ is chosen as the one which gives the lowest SSE is $18.79 \%$, while it is $23.16 \%$ for those who do not buy the add-on. That is, the policyholders who decide to buy the add-on continue to show lower risk in the year 2004 .

\section{CONCLUSION}

We have proposed an alternative way to turn a problem of asymmetric information into a solution of how to price insurance in groups with heterogeneous risk. The design of the proposed add-on can vary in many ways. Both the criterion of getting a dividend and the size of the dividend can easily be modified to suit a specific business line or area. For instance, no-claims are neither common nor relevant as a criterion for policyholders in areas with a high claim frequency, such as glass insurance within commercial transport. There, a criterion based on a bound on the number or cost of claims, either fixed or in relation to the expectation, might be more appropriate. However, as our intention has been to keep the model as simple and as descriptive as possible in this paper, we kept the criterion of no-claims. 
The size of the entrance fee will be a strategic decision based on either policyholder insight or the business strategy of the insurer, or by the policyholders themselves. We have showed that there might be both entrance fees and dividends that exist at realistic levels.

Under the assumptions made, we have found that each policyholder has an optimal entrance fee, depending on their initial wealth, individual risk profile and risk aversion. Since the insurer usually does not know the initial wealth or risk aversion of each individual, the insurer may let the policyholder choose the size of the entrance fee in order to get the optimal effect of the self-selection mechanism when pricing insurance. The higher the number of choices offered to the individual, the larger becomes the price-coverage differentiation, thereby increasing the competitiveness of the insurance product, due to fair pricing. However, the add-on will become less effective as a screening device. The more the price is differentiated, the less the add-on separates the policyholders into groups of buyers or not, and vice versa.

Although the one-period add-on analyzed in this paper is close to a classical BMS, its generalization to a multi-period add-on opens up avenues for further developments. Our approach is an alternative to a BMS, rather than a re-formulation of it, with a direct link to revealing a customer's asymmetric information. Exploring the pricing and efficiency of a multi-period add-on contract is a topic for future research.

The main conclusion of this paper is that the potential of the add-on increases with freedom of individual choice, while the efficiency is limited to the self-awareness of the individuals. But the most applicable conclusion is that by giving the policyholder an individually-set contingent payment based on their expected risk, instead of a collective fixed bonus rate, we get a fairer and more competitive pricing system.

\section{REFERENCES}

J. H. Abbring, P.-A. Chiappori, J. J. Heckman, and J. Pinquet. Adverse selection and moral hazard in insurance: can dynamic data help to distinguish? Journal of the European Economic Association, 1(2-3):512-521, 2003a.

J. H. Abbring, P.-A. Chiappori, and J. Pinquet. Moral hazard and dynamic insurance data. Journal of the European Economic Association, 1(4):767820,2003 b.

G. A. Akerlof. The market for "lemons": Quality uncertainty and the market mechanism. The Quarterly Journal of Economics, 84(3):488-500, 1970.

M. Allard, J.-P. Cresta, and J.C. Rochet. Pooling and separating equilibria in insurance markets with adverse selection and distribution costs. The Geneva Papers on Risk and Insurance Theory, 22:103-120, 1997.

F. Baione, S. Levantesi, and M. Menzietti. The development of an optimal bonus-malus system in a competitive market. ASTIN Bulletin, 32(1):159 170,2002 .

N. Brouhns, M. Guillén, M. Denuit, and J. Pinquet. Bonus-malus scales in 
segmented tariffs with stochastic migration between segments. The Journal of Risk and Insurance, 70(4):577-599, 2003.

H. Bühlmann and A. Gisler. A Course in Credibility Theory and its Applications. Springer Verlag, Berlin, 2005.

M. Denuit, X. Marechal, S. Pitrebois, and J.-F. Walhin. Actuarial Modelling of Claim Counts: Risk Classification, Credibility and Bonus-Malus Systems. John Wiley \& Sons, Ltd, England, 2007.

C. Donnelly, M. Englund, and J.P. Nielsen. Asymmetric information: Evidence from the automobile insurance market. Forthcoming, 2013.

M. Englund, M. Guillén, J. Gustafsson, L.H. Nielsen, and J.P. Nielsen. Multivariate latent risk: A credibility approach. ASTIN Bulletin, 38(1):137-146, 2008.

M. Englund, J. Gustafsson, J.P. Nielsen, and F. Thuring. Multidimensional credibility with time effects: An application to commercial business lines. The Journal of Risk and Insurance, 76(2):443-453, 2009.

I. Friend and M.E. Blume. The demand for risky assets. The American Economic Review, 65(5):900-922, 1975.

L. R. Glosten and P.R. Milgrom. Bid, ask and transaction prices in a specialist market with heterogeneously informed traders. Journal of Financial Economics, 14(1):71-100, 1985.

M. Guillén, J.P. Nielsen, T.H. Scheike, and A.M. Pérez-Marín. Time-varying effects in the analysis of customer loyalty: A case study in insurance. Expert Systems with Applications, 39(3):3551-3558, 2012.

E.J. Johnson, J. Hershey, J. Meszaros, and H. Kunreuther. Framing, probability distortions, and insurance decisions. Journal of Risk and Uncertainty, 7(1): $35-51,1993$.

H. Kim, D. Kim, S. Im, and J.W. Hardin. Evidence of asymmetric information in the automobile insurance market: Dichotomous versus multinomial measurement of insurance coverage. The Journal of Risk and Insurance, 76(2): 343-366, 2009.

D. Lazar and M. M. Denuit. Multivariate analysis of premium dynamics in P\&L insurance. The Journal of Risk and Insurance, 79(2):431-448, 2012.

J. Lemaire. Bonus-malus systems. In Encyclopedia of Actuarial Science. John Wiley \& Sons, Ltd, 2006.

J. Lemaire and H. Zi. A comparative analysis of 30 bonus-malus systems. ASTIN Bulletin, 24(2):287-309, 1994.

P. McCullagh and J.A. Nelder. Generalized Linear Models. Chapman \& Hall, London, 2nd edition, 1989.

I. Moreno, F. J. Vázquez, and R. Watt. Can bonus-malus allieviate insurance fraud? The Journal of Risk and Insurance, 73(1):123-151, 2006. 
R. S. Pindyck. Risk aversion and determinants of stock market behavior. The Review of Economics and Statistics, 70(2):183-190, 1988.

J. Pinquet. Allowance for cost of claims in bonus-malus systems. ASTIN Bulletin, 27(1):33-57, 1997.

J. Pinquet. Experience rating through heterogeneous models. In G. Dionne, editor, Handbook of Insurance, volume 22, pages 459-500. Springer Netherlands, 2001.

J. Pinquet, M. Guillén, and C. Bolancé. Allowance for the age of claims in bonus-malus systems. ASTIN Bulletin, 31(2):337-348, 2001.

O. Riedel. Unisex tariffs in health insurance. The Geneva Papers on Risk and Insurance, 31(2):233-244, 2006.

M. Rothschild and J. Stiglitz. Equilibrium in competitive insurance markets: An essay on the economics of imperfect information. The Quarterly Journal of Economics, 90(4):629-649, 1976.

A. Snow. On the possibility of profitable self-selection contracts in competitive insurance markets. Journal of Risk and Insurance, 76(2):249-259, 2009.

J. Spreeuw and M. Karlsson. Time deductibles as screening devices: Competitive markets. The Journal of Risk and Insurance, 76(2):261-278, 2009.

J.E. Stiglitz. Monopoly, nonlinear pricing and imperfect information: The insurance market. The Review of Economic Studies, 44(3):407-430, 1977.

G. G. Szpiro. Measuring risk aversion: An alternative approach. The Review of Economics and Statistics, 68(1):156-159, 1986.

F. Thuring, J.P. Nielsen, M. Guillén, and C. Bolancé. Selecting prospects for cross-selling financial products using multivariate credibility. Expert Systems with Applications, 39(10):8809 - 8816, 2012.

E. R. Ulm. Insurance pricing, reserving, and performance evaluation under external constraints on capitalization and return on equity. The Journal of Risk and Insurance, 79(2):541-566, 2012.

V. R. Young. Premium principles. In J. L. Teugels and B. Sundt, editors, Encyclopedia of Actuarial Science. John Wiley \& Sons, New York, 2006. 


\section{TABLES AND FIGURES}

TABLE 1 Claims summary of the data set

\begin{tabular}{lcccc}
\hline & \multicolumn{5}{c}{ Year $J$} \\
\hline$\sum_{i=1}^{I} \sum_{j=2001}^{J} n_{i j}$ & 2001 & 2002 & 2003 & 2004 \\
\hline$\sum_{i=1}^{I} \sum_{j=2001}^{J} \hat{\nu}_{i j}$ & 1604 & 3381 & 5264 & 7007 \\
\hline$\sum_{i=1}^{I} \mathbb{1}\left[\sum_{j=2001}^{J} n_{i j}=0\right]$ & 7128 & 6058 & 5165 & 4531 \\
\hline$\sum_{i=1}^{I} \mathbb{1}\left[\sum_{j=2001}^{J} n_{i j}<\sum_{j=2001}^{J} \hat{\nu}_{i j}\right]$ & 7128 & 6068 & 5365 & 5153 \\
\hline
\end{tabular}

Note: Cumulative number of experienced claims, cumulative number of expected claims, the number of policyholders with no claims, and the number of policyholders with fewer claims than expected, for each year of the period 2001-2004 for the data set of $I=8337$ policyholders. The actual and expected number of claims by policyholder $i$ in year $j$ is denoted $n_{i j}$ and $\hat{\nu}_{i j}$, respectively, and $\mathbb{1}$ denotes the zero-one indicator function.

TABLE 2 Pricing precision of various pricing methods

\begin{tabular}{clcc}
\hline $\begin{array}{c}\text { Pricing } \\
\text { method } l\end{array}$ & Description & $\begin{array}{c}\text { Scaled SSE } \\
=\frac{S S E(l, 2004)}{S S E(2,2004)}\end{array}$ & $\begin{array}{c}\text { Relative improvement } \\
=\frac{S S E(l, 2004)-S S E(2,2004)}{S S E(2,2004)-S S E(1,2004)}\end{array}$ \\
\hline 1 & Flat rate & 1.0324 & $\mathrm{~N} / \mathrm{A}$ \\
2 & Regression & 1.0000 & 1.0000 \\
3 & Credibility & 0.9918 & 0.2531 \\
4 & No-claims BMS & 0.9828 & 0.5309 \\
5 & Add-on & 0.3634 & 19.6482 \\
\hline
\end{tabular}

Note: Scaled SSE for each pricing method and the increase in the SSE over the regression method, relative to the improvement in the SSE by moving from the flat rate method to the regression method, for the year 2004. The actual $\operatorname{SSE}(2,2004)=2360$.

TABLE 3 Wealth at the end of insurance period $j$

\begin{tabular}{|c|c|c|c|}
\hline \multirow[b]{2}{*}{ Event } & \multirow[b]{2}{*}{$\begin{array}{l}\text { Conditional } \\
\text { probability }\end{array}$} & \multicolumn{2}{|c|}{ Decision } \\
\hline & & $\begin{array}{l}\text { Buy insurance } \\
\text { without add-on }\end{array}$ & $\begin{array}{c}\text { Buy insurance } \\
\text { with add-on }\end{array}$ \\
\hline$N_{i j}>0$ & $p_{i j}\left(\theta_{i}\right)$ & $w_{i j}-\mu_{i j}$ & $w_{i j}-\mu_{i j}-\pi_{i j}$ \\
\hline$N_{i j}=0$ & $1-p_{i j}\left(\theta_{i}\right)$ & $w_{i j}-\mu_{i j}$ & $w_{i j}-\mu_{i j}+d_{i j}$ \\
\hline
\end{tabular}

Note: The wealth at the end of insurance period $j$ depends on the decision to buy the add-on or not, and whether the policyholder has no-claims or not, assuming a null discount rate. 
TABLE 4 Pricing precision with optimal constant investment ratio

\begin{tabular}{llllll}
\hline & \multicolumn{5}{c}{ Initial wealth $w_{i, 2004}$ in DKK } \\
\cline { 2 - 6 } & 10000 & 20000 & 50000 & 100000 & 1000000 \\
\hline Optimal constant $\beta$ & 0.06203 & 0.06226 & 0.06188 & 0.05431 & 0.01395 \\
$S S E(5,2004) / S S E(2,2004)$ & 0.9735 & 0.9483 & 0.8804 & 0.7866 & 0.5534 \\
$\frac{S S E(5,2004)-S S E(2,2004)}{S S E(2,2004)-S S E(1,2004)}$ & 0.8179 & 1.5957 & 3.6914 & 6.5864 & 13.7840 \\
Number of buyers of add-on & 3679 & 3670 & 3687 & 4078 & 5147 \\
\hline
\end{tabular}

Note: Optimal investment ratio if all policyholders are proposed with the same investment ratio and are assumed to have the same risk aversion coefficient $\gamma=2$ and the same initial wealth $w_{i, 2004}$. The optimal investment ratio is the one which minimizes the SSE. The values of $S S E(2,2004)$ and $S S E(1,2004)$ are derived from Table 2.

TABLE 5 Pricing precision with individually optimal investment ratio

\begin{tabular}{llllll}
\hline & \multicolumn{5}{c}{ Initial wealth $w_{i, 2004}$ in DKK } \\
\cline { 2 - 6 } & 10000 & 20000 & 50000 & 100000 & 1000000 \\
\hline$S S E(5,2004) / S S E(2,2004)$ & 0.9707 & 0.9427 & 0.8659 & 0.7623 & 0.4125 \\
$S S E(5,2004)-S S E(2,2004)$ & 0.9043 & 1.7685 & 4.1389 & 7.3364 & 18.1327 \\
$S S E(2,2004)-S S E(1,2004)$ & 5246 & 5246 & 5246 & 5246 & 5246 \\
\hline Number of buyers of add-on & 1046 &
\end{tabular}

Note: Scaled SSE when the estimated value of the optimal investment ratio $\tilde{\beta}_{i, 2004}$ of each individual is used as entrance fee, and each policyholder is assumed to have the same initial wealth $w_{i, 2004}$ and risk aversion coefficient $\gamma=2$. The number of buyers of the add-on is constant, as their optimal investment ratio is independent of wealth. The values of $S S E(2,2004)$ and $S S E(1,2004)$ are derived from Table 2.

TABLE 6 Pricing precision with entrance fee a multiple of the individual annual insurance premium

\begin{tabular}{llllll}
\hline & \multicolumn{5}{c}{ Initial wealth $w_{i, 2004}$ in DKK } \\
\cline { 2 - 6 } & 10000 & 20000 & 50000 & 100000 & 1000000 \\
\hline$\hat{\pi}_{i, 2004} / \hat{\mu}_{i, 2004}^{(2)}$ & 0.06366 & 0.2851 & 0.8576 & 1.605 & 3.566 \\
$S S E(5,2004) / S S E(2,2004)$ & 0.9837 & 0.9560 & 0.8948 & 0.8147 & 0.6046 \\
$S S E(5,2004)-S S E(2,2004)$ & 0.5031 & 1.3580 & 3.2469 & 5.7191 & 12.2037 \\
$S S E(2,2004)-S S E(1,2004)$ & 4781 & 4147 & 4010 & 4178 & 5148 \\
\hline Number of buyers of add-on & 478 &
\end{tabular}

Note: Scaled SSE for different initial wealth $w_{i, 2004}$, when the entrance fee is a multiple of the individual annual insurance premium. The multiple is the same for each policyholder across the data set, while the annual insurance premium is individual. Here, the policyholders choose individually whether to accept the add-on or not. The values of $S S E(2,2004)$ and $S S E(1,2004)$ are derived from Table 2. 
FIGURE 1 Distribution of the estimated values of $\frac{p_{i, 2004}}{1-p_{i, 2004}}$

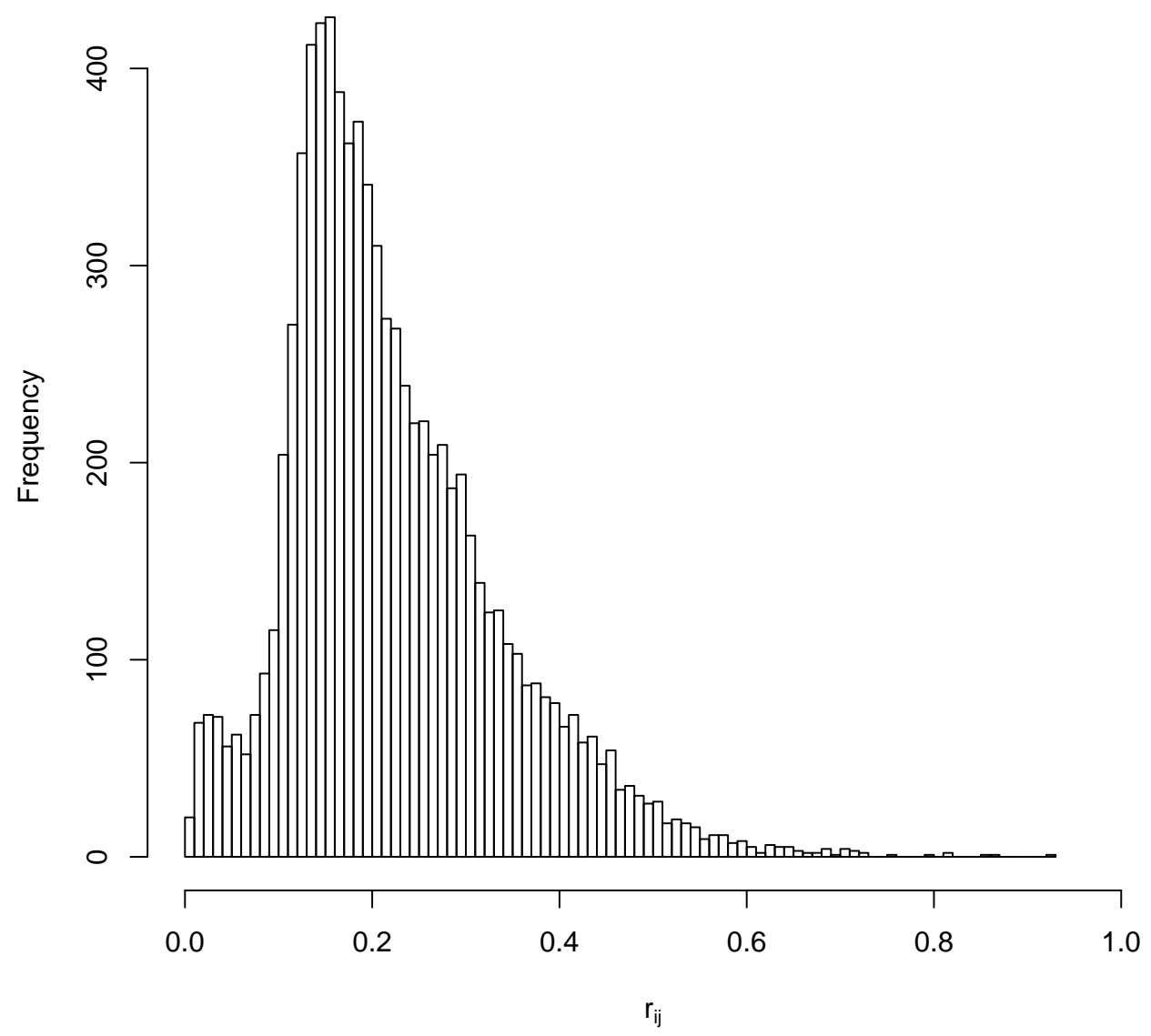

Note: As we use equation (2) to calculate the dividend $d_{i, 2004}$ then, by equation (4), $r_{i, 2004}=p_{i, 2004} /\left(1-p_{i, 2004}\right)$ for policyholder $i$. 
FIGURE 2 Pricing precision of the add-on

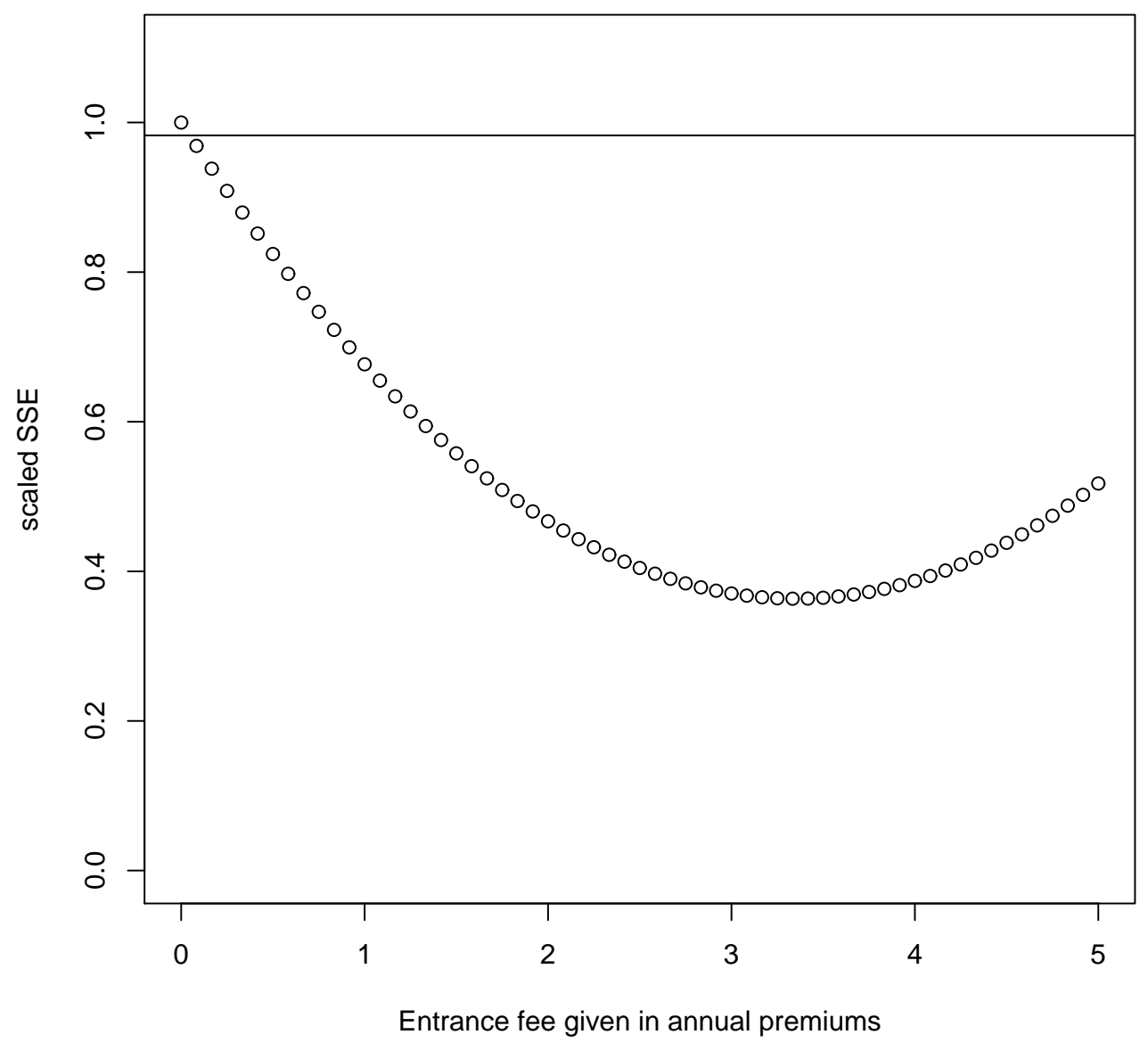

Note: Here the entrance fee of policyholder $i$ is calculated as $\pi_{i, 2004}=k \hat{\mu}_{i, 2004}^{(2)}$, for $k \in\{0,1 / 12,2 / 12, \ldots, 5\}$ and all policyholders are assumed to accept the add-on. The circles in the figure show the scaled SSE of the add-on contract in the year 2004 for different values of $k$. The minimum scaled SSE occurs at $k=3.357$. The horizontal line is the scaled SSE of the no-claims BMS method. For an entrance fee of $\frac{1}{12} \hat{\mu}_{i, 2004}^{(2)}$ or more, the SSE is lower for the add-on than for the no-claims BMS method, in the investigated range. 
FIGURE 3 Demand curve of the add-on.

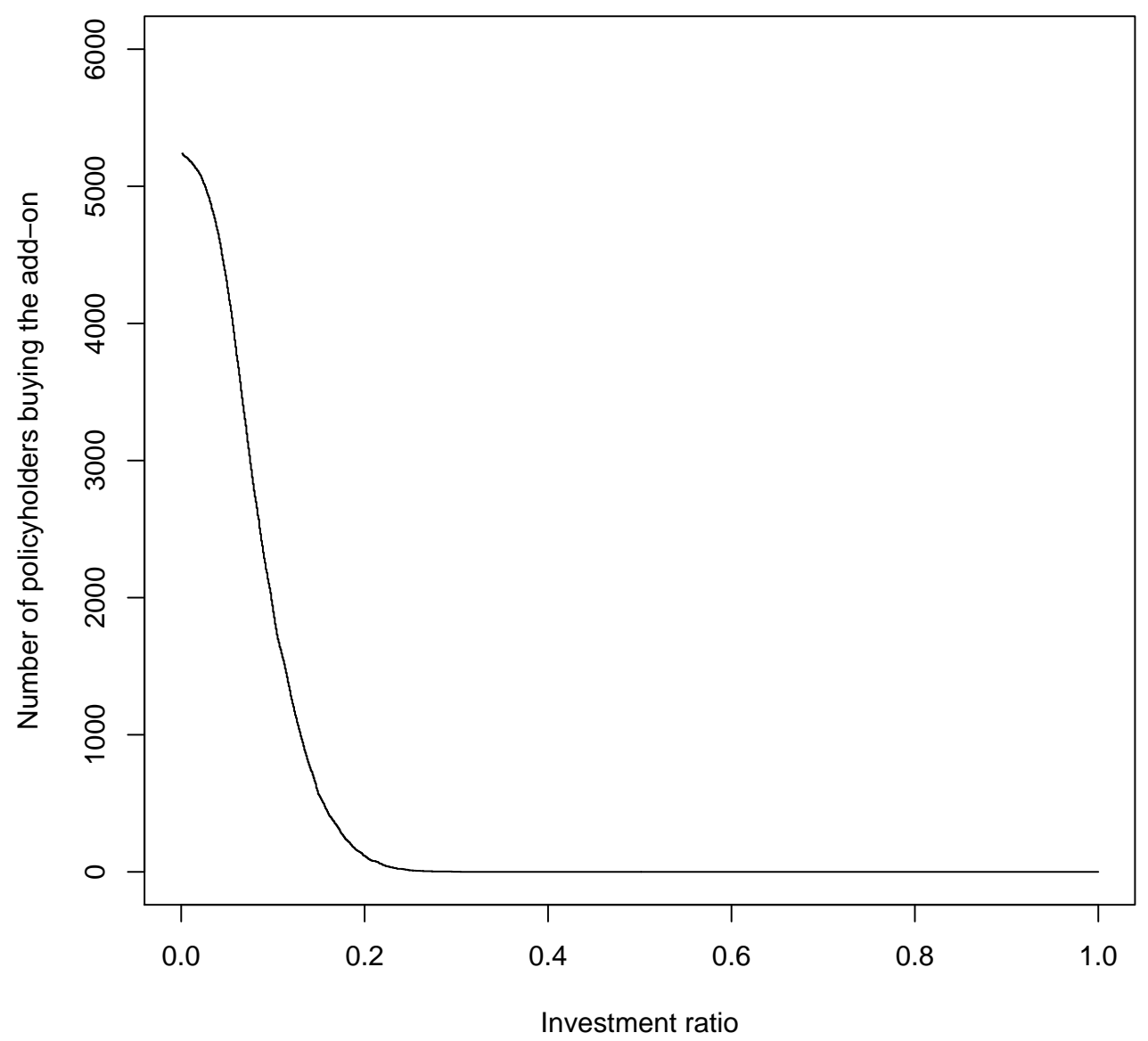

Note: The number of policyholders who would buy the add-on, based on the decision rule (5), as the constant investment ratio $\beta$ offered to all policyholders increases. 
FIGURE 4 Distribution of the estimated values of the individually optimal investment ratio $\tilde{\beta}_{i, 2004}$

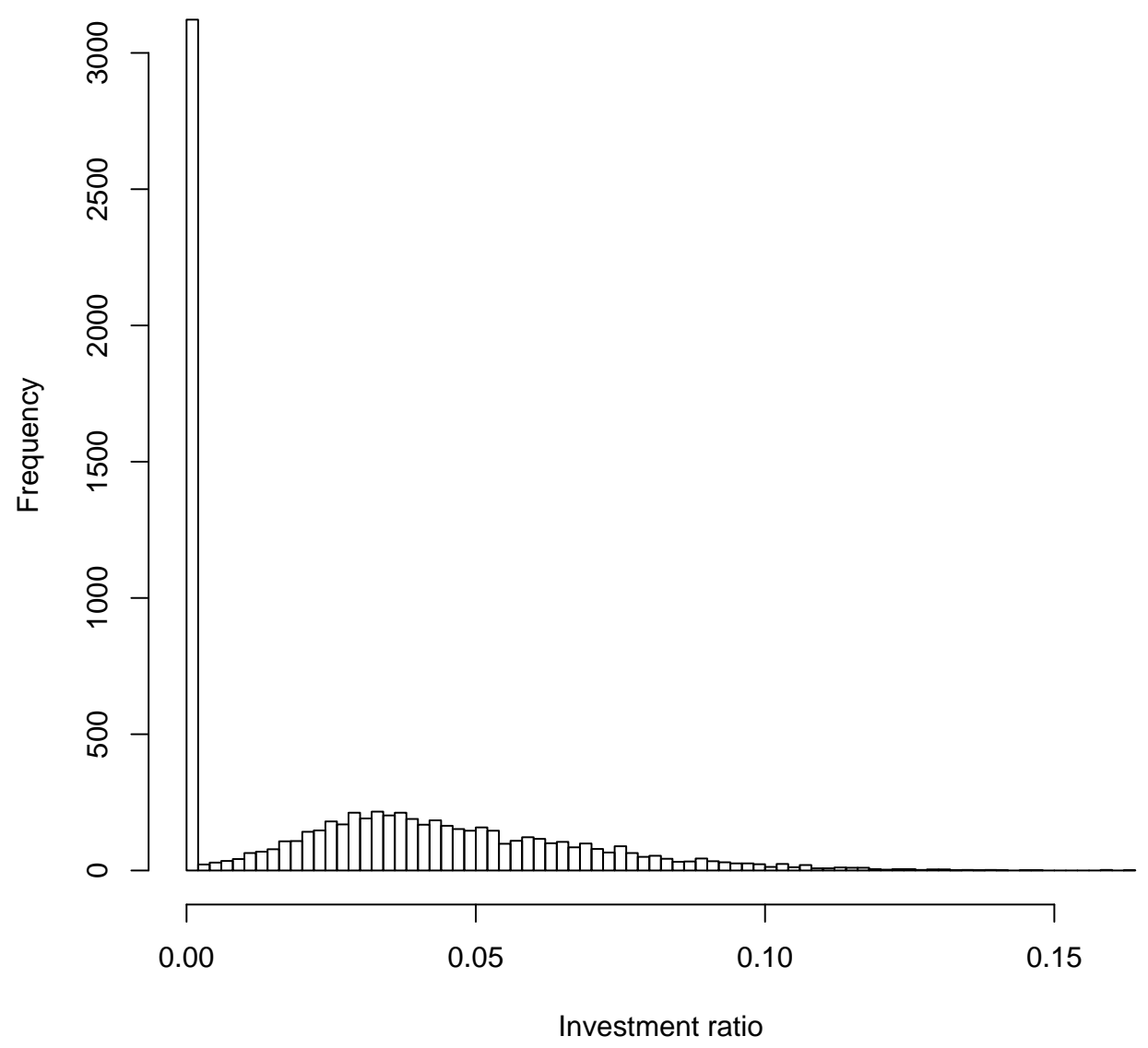

Note: There are 3091 policyholders who will decide to not accept the add-on, regardless of the offered investment ratio, as the estimated value of their conditional probability of claims $p_{i, 2004}\left(\theta_{i}\right)$ is greater than the estimated value of their unconditional probability $p_{i, 2004}$ (recall decision rule (5)). The optimal investment ratio for these policyholders is set to zero. 